\title{
Electromagnetic Torque Estimation of a Three-Phase Induction Motor for Setting the Feedrate of a Milling Machine
}

\author{
Élida Fernanda Xavier Júlio ${ }^{1}$, Simplício Arnaud da Silva ${ }^{2}$, Cícero da Rocha Souto ${ }^{2}$ and Isaac Soares de Freitas ${ }^{2}$ \\ 1. Postgraduation Program in Mechanical Engineering, Federal University of Paraiba, João Pessoa 58059-900, Brazil \\ 2. Department of Electrical Engineering, Federal University of Paraíba, João Pessoa 58059-900, Brazil
}

Received: March 11, 2014 / Accepted: March 31, 2014 / Published: June 25, 2014.

\begin{abstract}
In this paper, it presents a project of a fuzzy controller and a neural estimator to control a coordinate table powered by three-phase induction motor, aiming to implement an intelligent milling system. The position/speed control is performed using vector techniques of three-phase induction machines. The estimation of the motor electromagnetic torque is used for setting the feedrate of the table. The speed control is developed using TS (Takagi-Sugeno) fuzzy logic model and electromagnetic torque estimation using neural network type LMS (least mean square) algorithm. The induction motor is powered by a frequency inverter driven by a DSP (digital signal processor). Control strategies are implemented in DSP. Simulation results are presented for evaluating the performance of the system.
\end{abstract}

Key words: Machining, speed control, torque estimation, fuzzy logic, neural network.

\section{Introduction}

Milling is a machining process in which the piece material removal takes place intermittently. The milling is accomplished by the combination of two movements performed simultaneously. One of the movements is rotation of the cutter around its axis. The other is the movement of the milling machine table, which is attached to the piece to be milled. Thus, cutting parameters such as feedrate, cutting speed and cutting depth should be analyzed [1]. According to Ref. [2], parameters of the machining process should be monitored and adjusted automatically, which can improve the production quality and reduce the machining time.

With advancements in applications using induction motors, the use of these motors on start and

Corresponding author: Élida Fernanda Xavier Júlio, Ph.D. student, electrical engineer, research fields: control systems, electric drives, fuzzy logic and artificial neural network. E-mail: elida_xnet@yahoo.com.br. controlling of positioning systems are majority in the industry. An example of positioner machine is the coordinate table, which has applicability to devices milling, turning, drilling, and welding, among others. The milling operation is one of the most important in the process of mechanical machining.

The three-phase induction motor is widely used in various applications in industry, due to its relative simplicity of construction, maintenance, both operational and market low cost, as well as, the capacity to operate with a wide range of loads in adverse conditions. One of the factors that provided the advancement in driving of three-phase induction motor was the development of control strategies, specifically vector control strategies.

In induction machine, the implementation of vector control for field orientation can be done by direct or indirect method. The direct field orientation enables the position of the flux to be determined by measuring terminal quantities of the stator (voltages and currents). 
The advantage of using the stator terminal quantities lies in the fact to be sensitive only to the stator resistance [3].

In the development of controllers and estimators, the use of vector control and the application of intelligent control techniques, such as fuzzy logic and ANN (artificial neural network), provided greater robustness to systems powered by three-phase induction motors.

Fuzzy logic is a technique that allows the implementation of human experience in systems, considering the uncertainty of information, the ambiguities, for the development of controllers. The fuzzy inference model type TS (Takagi-Sugeno) is capable of representing, approximately or exactly, any nonlinear dynamics as combination of locally valid linear models, interpolating smoothly [4]. The TS fuzzy model is a hybrid approach [5], because it combines a fuzzy method based on rules and a mathematical method, consisting of conditional propositions, whose antecedents are linguistic variables and whose consequents are linear equations [6].

The ANN is a computational technique organized according on human neural structures and acquires knowledge from experience, consisting of inherently parallel and adaptive processing [7]. This technology has the proper way to store knowledge and evaluate them for use [8]. This knowledge is acquired through a learning process and stored in a distributed manner. The learning objective is to obtain an implicit model of the system under study by adjusting the parameters of the neural network [9].

In machining systems, a structure consisting of ANN and data set was applied in Ref. [10] in order to obtain the inference of knowledge of a fuzzy model for an end milling process. The inference, based on fuzzy learning, was used as a mechanism of intelligent determination of advancement.

The signal digital processor is a device that performs signal acquisition and large number of mathematical operations with fast and efficient processing in the range of microseconds, enabling the application in high performance systems operating in real time [11]. This equipment is well suited for the implementation of control and estimation strategies, which have complex calculations to be performed in real time.

This paper presents simulated results for the development of a driving and control system of a vertical milling machine. This system drives the coordinate table of the milling machine with specific feedrate for machining of material of a piece.

As the coordinate table is driven by three-phase induction motor, the angular position control and the rotor rotational speed control of this motor are carried out. This speed of the three-phase induction motor is controlled using TS fuzzy control system.

The electromagnetic torque of the motor is estimated in order to identify the material of the machined piece and to define the feedrate of the table. For this estimation, it is used an ANN type LMS (least mean square) algorithm.

The paper is organized as follows: Section 2 presents the development of the driving and control system of the milling machine table; Section 3 shows the simulation results obtained; and Section 4 presents the comments and conclusions about this paper and the perspective of future work.

\section{System Development}

For the experimental setup of the milling machine, design shown in Fig. 1, it will be used an $X-Y$ coordinate table composed by two perpendicular bases to each other, $X$ and $Y$, which move linearly in the horizontal plane. The $X$ base of the table (upper base) has a course of $200 \mathrm{~mm}$ and the $Y$ base (lower base) of $100 \mathrm{~mm}$, whose trapezoidal spindles have a pitch of 4 $\mathrm{mm}$ for ten revolutions of the motor shaft. Each base of the table is driven by a three-phase induction motor. The drive of the $X$ base results in displacements in the right and left directions, and the $Y$ base results in forward and backward displacements. 


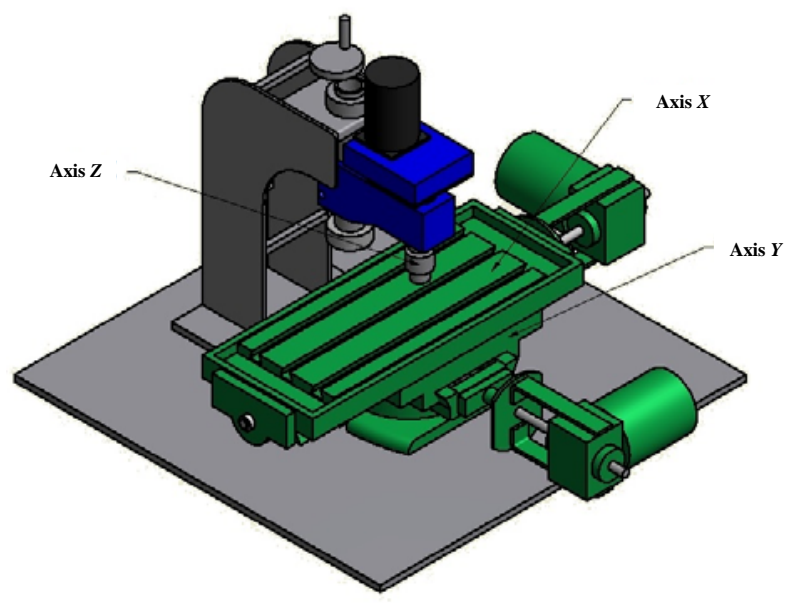

Fig. 1 Vertical milling machine design.

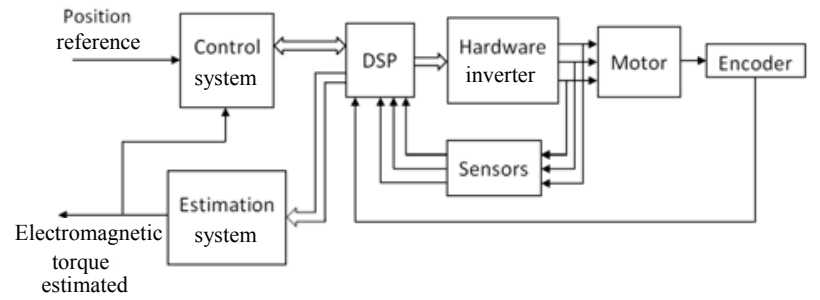

Fig. 2 Schematic diagram for the control of the coordinate table.

A tool of end mill will be attached on the mandrel, located in the spindle of the milling machine. The cutter, running through a cutting depth in the $Z$ axis, will perform chip removal of a piece fixed to the $X$ base.

Due to the work of piece machining, an electromagnetic torque will be imposed on the induction motor of the $X$ base. The information of the electromagnetic torque estimated will characterize the type of material constituent of the piece. This signal of the estimated torque will be used to specify, in real time, the drive speed of the $X$ base.

In Fig. 2, the system configuration for the drive and control of the $X$ base of the coordinate table is schematized. In this diagram, it can be observed not only the control system, developed to drive and control the three-phase induction motor of the $X$ base, but also the estimation system of the electromagnetic torque of this motor.

A DSP is used for processing, transmission and data acquisition. Hardware consists of a three-phase voltage inverter will power the three-phase induction motor of the table. An encoder is coupled to the motor shaft in order to obtain the angular position of the rotor of this machine and thus the linear position of the $X$ base. And sensors are used to obtain the phase currents and phase voltages of the motor.

\subsection{Control System}

The control system of the three-phase induction motor was implemented in closed loop, where it was developed: a current controller using a PI (proportional-integral) controller and a speed controller through fuzzy model TS.

The speed controller is composed of a fuzzy PD base, TS model with an input of Error and another Derror and the integration of the Error. In Fig. 3, it is presented the structure of the PD + I speed fuzzy controller used, in which $i_{t s}$ is the output variable of the fuzzy PD base, $k_{p}$ is the gain and $i_{s q}^{b^{*}}$ is the control variable. The variable $i_{s q}^{b^{*}}$ corresponds to the stator current of the three-phase induction motor, $q$ component in referential of the rotor flux.

Next, the settings for fuzzification, fuzzy inference and defuzzification of the developed fuzzy PD base are presented.

In the fuzzification stage, Error and Derror input variables are defined, respectively, by the difference between the reference value and the value of the rotor rotational speed $\omega_{r}$, and by the derivative of this error. The universes of discourse of the Error and Derror comprise a normalized range from -1 to 1 .

The variable Error is composed of seven pertinence functions with triangular and trapezoidal shapes

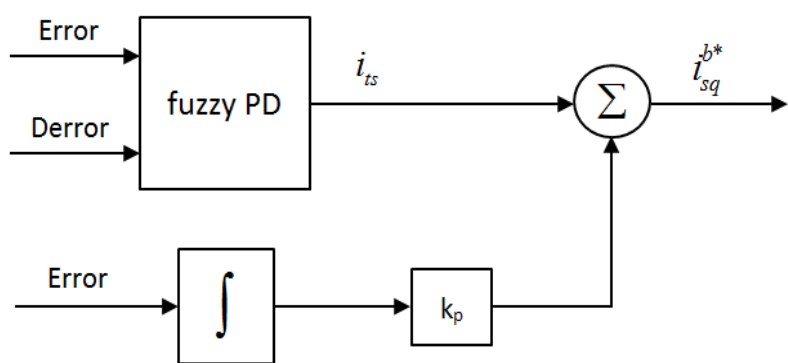

Fig. 3 PD + I speed fuzzy controller. 
called: NB (negative big), NM (negative medium), NS (negative small), AZ (almost zero), PS (positive small), PM (positive medium) and PB (positive big). In Fig. 4, it is presented the arrangement of linguistic terms of the Error in their universe of discourse.

For variable Derror, it was associated seven pertinence functions, with triangular and trapezoidal shapes, defined by the terms: NB, NM, NS, AZ, PS, $\mathrm{PM}$ and PB. In Fig. 5, these functions are shown.

In the stage of fuzzy inference, it is determined how the control rules are activated. In Table 1, the forty-nine control rules developed are inserted.

Control rules consist of conditional sentences. For the composition of each rule and for the relationship between them, the max-min inference technique was used. Thus, each sentence is modeled by the minimal application and the relationships between rules are modeled by the maximal application.
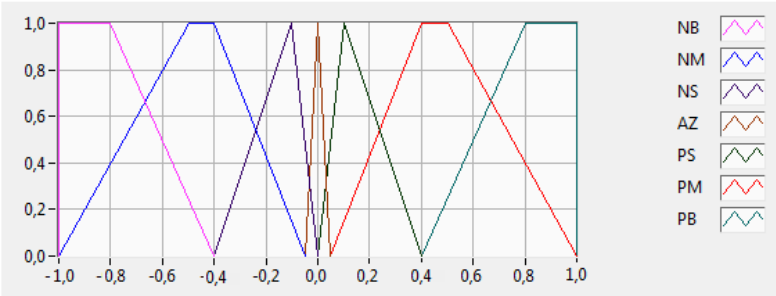

Fig. 4 Pertinence functions of the Error input variable.

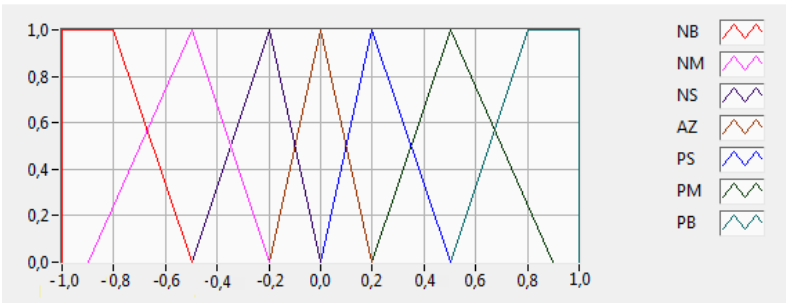

Fig. 5 Pertinence functions of the Derror input variable.

Table 1 Table of fuzzy rules of the speed controller.

\begin{tabular}{llllllll}
\hline \multicolumn{2}{c}{ Derror } \\
Error & $\mathrm{NB}$ & $\mathrm{NM}$ & $\mathrm{NS}$ & $\mathrm{AZ}$ & $\mathrm{PS}$ & $\mathrm{PM}$ & $\mathrm{PB}$ \\
\hline $\mathrm{NB}$ & $i N B$ & $i N B$ & $i N B$ & $i N B$ & $i P M$ & $i P B$ & $i P B$ \\
$\mathrm{NM}$ & $i N B$ & $i N B$ & $i N B$ & $i N M$ & $i P S$ & $i A Z$ & $i P B$ \\
$\mathrm{NS}$ & $i N B$ & $i N B$ & $i N M$ & $i N S$ & $i A Z$ & $i P S$ & $i P M$ \\
$\mathrm{AZ}$ & $i P B$ & $i P M$ & $i P S$ & $i A Z$ & $i N S$ & $i N M$ & $i N B$ \\
$\mathrm{PS}$ & $i N M$ & $i N S$ & $i A Z$ & $i P S$ & $i P M$ & $i P B$ & $i P B$ \\
$\mathrm{PM}$ & $i N B$ & $i A Z$ & $i N S$ & $i P M$ & $i P B$ & $i P B$ & $i P B$ \\
$\mathrm{~PB}$ & $i N B$ & $i N B$ & $i N M$ & $i P B$ & $i P B$ & $i P B$ & $i P B$ \\
\hline
\end{tabular}

In the defuzzification, the $i_{t s}$ output variable is generated, according to the PD fuzzy output shown in Fig. 3. According to TS fuzzy method, at this stage, a linear and time-invariant model is determined [12].

In Eq. (1), $i_{t s}$ variable is obtained by a weighted average, in which the $i_{t s x}, i_{t s y}$ and $i_{t s z}$ terms are expressed by Eqs. (2)-(4), respectively. This equation consists of linear functions, defined from the consequents of control rules and the numerical values of the Error and Derror input variables.

$$
\begin{aligned}
i_{t s}=\frac{i_{t s x}+i_{t s y}+i_{t s z}}{i N B+} & i N M+i N S+i A Z+i P B+i P M+i P S \\
i_{t s x}= & i N B(30 \cdot \text { Error }-0.1 \cdot \text { Derror })+ \\
& i N M(70 \cdot \text { Error }-0.3 \cdot \text { Derror })+ \\
& i N S(90 \cdot \text { Error }-0.5 \cdot \text { Derror }) \\
i_{t s y}= & i A Z(1.0 \cdot \text { Error }-1.0 \cdot \text { Derror }) \\
i_{t s z}= & i P B(30 \cdot \text { Error }-0.1 \cdot \text { Derror })+ \\
& i P M(70 \cdot \text { Error }-0.3 \cdot \text { Derror })+ \\
& i P S(90 \cdot \text { Error }-0.5 \cdot \text { Derror })
\end{aligned}
$$

The project of the current controller was developed from the complex model of representation of a three-phase induction machine, using the control quadrature with referential in rotor flux (b).

Through the realization of mathematical simplifications, it was obtained the transfer function used in the project of current controller as in Eq. (5), where $I_{s}^{b}$ and $V_{s}^{b^{\prime}}$ correspond to the stator current and stator voltage of the three-phase induction motor in the referential of the rotor flux, respectively. Eqs. (6) and (7) are constituted by the parameters of the three-phase induction motor, in which $l_{s}$ is the cyclic stator inductance, $l_{r}$ is the cyclic rotor inductance, $l_{m}$ is the cyclic mutual inductance, $R_{s}$ is the stator resistance and $\tau_{r}$ is the rotor time constant.

$$
\begin{gathered}
I_{s}^{b}=\frac{l_{r} \sigma}{(s+\eta)} V_{s}^{b^{\prime}} \\
\sigma=\frac{1}{l_{s} l_{r}-l_{m}^{2}} \\
\eta=l_{r} \sigma R_{s}+\frac{\sigma l_{m}^{2}}{\tau_{r}}
\end{gathered}
$$

For the development of the current controller, a PI classical controller whose gains $k_{p_{i}}$ and $k_{i_{i}}$ were 
determined by Eqs. (8) and (9), respectively, was used. In Eq. (8), $T_{v}$ is the time constant of the source.

$$
\begin{aligned}
& k_{p_{i}}=\frac{1}{4 T_{v} l_{r} \sigma} \\
& k_{i_{i}}=\eta \cdot k_{p_{i}}
\end{aligned}
$$

\subsection{Estimation System}

From the complex model of representation of three-phase induction machine, it developed the estimation project of the electromagnetic torque of the three-phase induction motor, using control quadrature with fixed reference in the stator (a) and applying a ANN type LMS algorithm.

An equation widely used to estimate the electromagnetic torque is Eq. (10), which is written in terms of the components of the stator flux and stator current. Thus, for the estimation of electromagnetic torque, stator flux of the three-phase induction motor was firstly estimated.

$$
c e=P\left(i_{s q}^{a} \lambda_{s d}^{a}-i_{s d}^{a} \lambda_{s q}^{a}\right)
$$

In applying the voltage model of the machine and in the direct field orientation with reference by stator flux, the estimate stator flux $\lambda_{s}^{a}$ is obtained by integrating the counter-electromotive force. Eqs. (11) and (12) correspond to the stator flux in the $d$ and $q$ components, respectively. The stator voltage $v_{s}^{a}$ and stator current $\mathrm{i}_{s}^{a}$ variables were obtained from the motor terminals. The stator resistance $R_{s}$ is considered constant and equal to $5.1 \Omega$.

$$
\begin{aligned}
& \lambda_{s d}^{a}=\int\left(v_{s d}^{a}-R_{s} i_{\mathrm{sd}}^{a}\right) \mathrm{d} t \\
& \lambda_{s q}^{a}=\int\left(v_{s q}^{a}-R_{s} i_{\mathrm{sq}}^{a}\right) \mathrm{d} t
\end{aligned}
$$

The integration procedure of counter-electromotive force originates levels of continuous current called offset in the estimation of the stator flux, implying, therefore, on an estimation of electromagnetic torque with not tolerable errors.

For eliminating the offset on the flux signal, a neural adaptive filter was developed by the LMS algorithm technique. A neural structure was implemented for each flux component, $d$ and $q$, similarly.

In Fig. 6, this structure is presented for the $d$ component, consisting of only one neuron and a bias, as synaptic weight, with constant input equal to 1 . The neural structure has, as input, the signal from the estimated stator flux $\lambda_{s d}^{a}$ and the filtrated estimated stator flux $\lambda_{s d f}^{a}$ is obtained in the output. The filtering process is performed by subtracting " $y$ " of the input signal $\lambda_{s d}^{a}$.

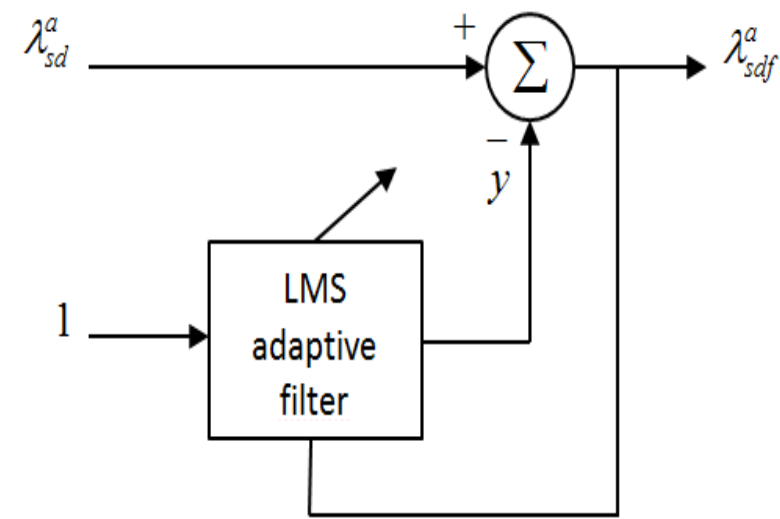

Fig. 6 Neural structure with LMS adaptive filter.

The algorithm developed for representation of the neural structure is described in Eqs. (13) and (14), where $y(n)$ is the filter output at the current instant and $y(n+1)$ is the filter output at the next instant. Through this algorithm, an adaptive iteration was effected to each acquisition of the input data.

$$
\begin{gathered}
\lambda_{s d f}^{a}=\lambda_{s d}^{a}-y(n) \\
y(n+1)=y(n)+2 \mu \lambda_{s d f}^{a}
\end{gathered}
$$

The learning rate $\mu$ used in Eq. (14) was calculated by Eq. (15), so that $\mu$ is obtained in function of speed $\omega_{r}$ because specific learning rates, due to variation of speed $\omega_{r}$, were required.

$$
\mu=-3.5625 \cdot 10^{-7} \cdot \omega_{\mathrm{r}}+2.4884375 \cdot 10^{-4}
$$

After the estimation of the stator flux and the elimination of the offset in the flux signal, the electromagnetic torque of the motor was estimated using Eq. (16). In Eq. (16), the estimated 
electromagnetic torque $c e_{e s t}$ is determined using the filtered estimated stator flux, $\lambda_{s d f}^{a}$ and $\lambda_{s q f}^{a}$, the stator current, $i_{s d}^{a}$ and $i_{s q}^{a}$, and the constant of the number of pairs of poles $P$ of the three-phase induction motor, which is equal to two.

$$
c e_{e s t}=P\left(i_{s q}^{a} \lambda_{s d f}^{a}-i_{s d}^{a} \lambda_{s q f}^{a}\right)
$$

\section{Simulation Results}

In milling system, the objective is to drive the $X$ base of the table for machining pieces constituted by different materials. To perform this study in the simulation of the operation of the three-phase induction motor, the application of various loads to the motor was simulated and information of the torque signal $c e_{\text {est }}$ was used in the specification of the speed reference of rotation of the rotor $\omega_{r}^{*}$ for the motor drive.

The milling machine table performs a displacement of $4 \mathrm{~mm}$ for every ten revolutions of the motor shaft. Therefore, it was determined a numerical factor of the relationship between the magnitudes of linear displacement and linear speed of the table and the magnitudes of angular displacement and angular speed of the three-phase induction motor, that is 0.064 $\mathrm{mm} / \mathrm{rad}$.

In Table 2, the values, in module, are shown: the electromagnetic torques $c e$ and their speed references $\omega_{r}^{*}$, and, through the ratio factor, the equivalent speed references of the $X$ base $v^{*}$.

For analysis of the response curves, the induction motor is driven by references the type of step position, with amplitudes of 1,562.5 rad and -1,562.5 rad, resulting in rotation of the motor shaft in clockwise and anticlockwise directions. The aim is to analyze the displacement of the $X$ base in right and left directions, along its $200 \mathrm{~mm}$ course.

The simulated three-phase induction motor has the following parameters: $R_{s}=5.1 \Omega, R_{r}=4.4578 \Omega, l_{s}=l_{r}$ $=0.334 \mathrm{H}, l_{m}=0.3185 \mathrm{H}, F=0.0041 \mathrm{Nms}$ and $J=$ $0.041 \mathrm{kgm}^{2}$. The simulation was performed in $\mathrm{C}$
Table 2 Electromagnetic torques and reference speeds (values in module).

\begin{tabular}{lll}
\hline$c e(\mathrm{Nm})$ & $\omega_{r}^{*}(\mathrm{rad} / \mathrm{s})$ & $v^{*}(\mathrm{~mm} / \mathrm{s})$ \\
\hline 1.0 & 31.0 & 1.984 \\
2.0 & 27.0 & 1.728 \\
3.0 & 23.0 & 1.472 \\
4.0 & 19.0 & 1.216 \\
5.0 & 15.0 & 0.960 \\
\hline
\end{tabular}

language using the $\mathrm{C}++\mathrm{Builder}{ }^{\circledR} \quad \mathrm{XE}$ computer program and response curves were plotted using the Matlab $^{\mathrm{TM}}$ program.

\subsection{First Simulation}

Initially, in Fig. 7, the response and reference curves of the variable angular position of the rotor are presented. In this first simulation, the induction motor was driven with a step type reference signal with amplitude of 1,562.5 rad, applying a load of $1 \mathrm{Nm}$ from starting of the machine and, after $30 \mathrm{~s}$ of operation, a load of $3 \mathrm{Nm}$ was applied. Due to load applications, electromagnetic torques were imposed to the three-phase induction motor.

In Fig. 8, the response and reference curves of the variable position of the $X$ base are shown, in which the step reference signal with amplitude of $100 \mathrm{~mm}$ is equivalent to a step of 1,562.5 rad. This amplitude of linear magnitude corresponds to a displacement of the $X$ base of the table to position $100 \mathrm{~mm}$. Through the graphics of Figs. 7 and 8, it was possible to verify a settling time of $57.72 \mathrm{~s}$, a steady state error of $0.13 \%$ and non-occurrence of overshoot.

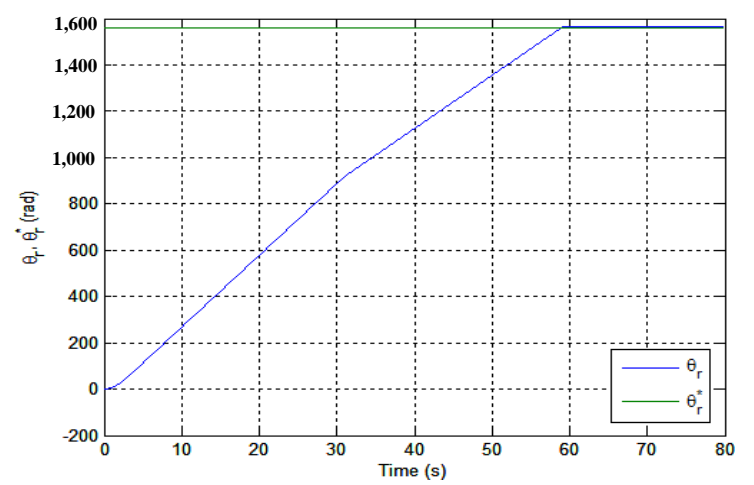

Fig. 7 Response and reference curves of the angular position of the rotor. 

the Feedrate of a Milling Machine

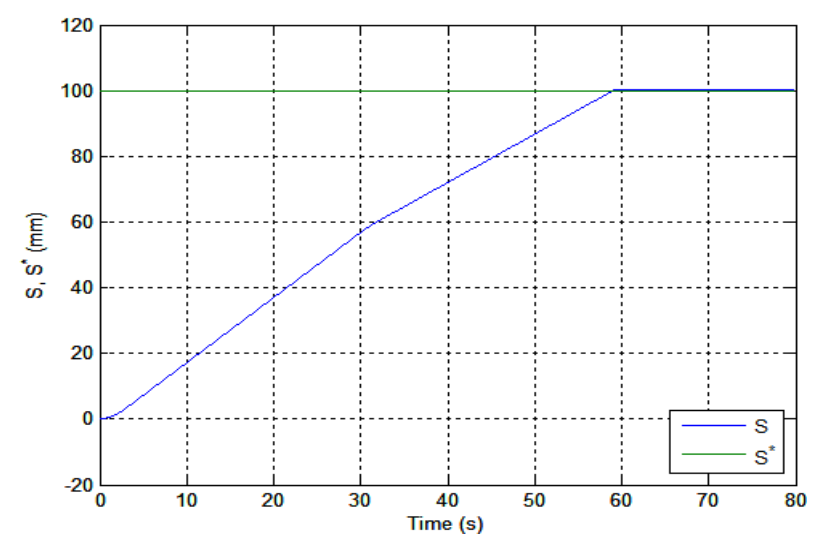

Fig. 8 Response and reference curves of the position of the $X$ base.

Then, in Fig. 9, the reference curve of rotational speed of the rotor and the response curve obtained are presented. In this curve, it can be observed the three-phase induction motor drive by a ramp signal speed with amplitude of $31 \mathrm{rad} / \mathrm{s}$, in the upward direction, keeping constant speed until the instant of 30 s. This constant speed of $31 \mathrm{rad} / \mathrm{s}$ corresponds to the $\omega_{r}^{*}$ excitation due to an estimation of electromagnetic torque of $1 \mathrm{Nm}$, according to Table 2 . At the instant 30 $\mathrm{s}$, due to the estimation of electromagnetic torque of 3 $\mathrm{Nm}$, a speed ramp with an amplitude of $23 \mathrm{rad} / \mathrm{s}$ was observed in the downward direction, remaining constant up to a drive $\omega_{r}^{*}$ at null value, thus, resulting in the braking of the three-phase induction motor.

In Fig. 10, the response and reference curves of the $X$ base speed are shown, in which the amplitude of 1.984 $\mathrm{mm} / \mathrm{s}$ of the ramp reference was equivalent to the 31 $\mathrm{rad} / \mathrm{s}$ amplitude, and amplitude of $1.472 \mathrm{~mm} / \mathrm{s}$ was equivalent to the amplitude of $23 \mathrm{rad} / \mathrm{s}$. By analyzing the graphics of Figs. 9 and 10, null steady state errors were observed in the time interval in which speed references were constant.

Following, the response and reference curves of the stator current in the $d$ and $q$ components were analyzed, as shown in Figs. 11 and 12, respectively. In these graphics, the control of both components of the stator current was verified. In Fig. 12, it was possible to observe the behavior of the $i_{s q}^{b^{*}}$ control variable curve, generated by the fuzzy controller of speed, verifying

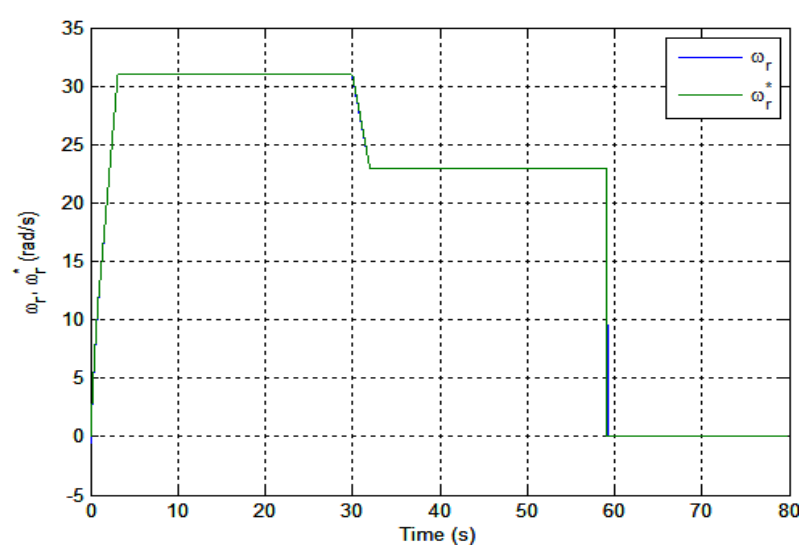

Fig. 9 Response and reference curves of rotational speed of the rotor.

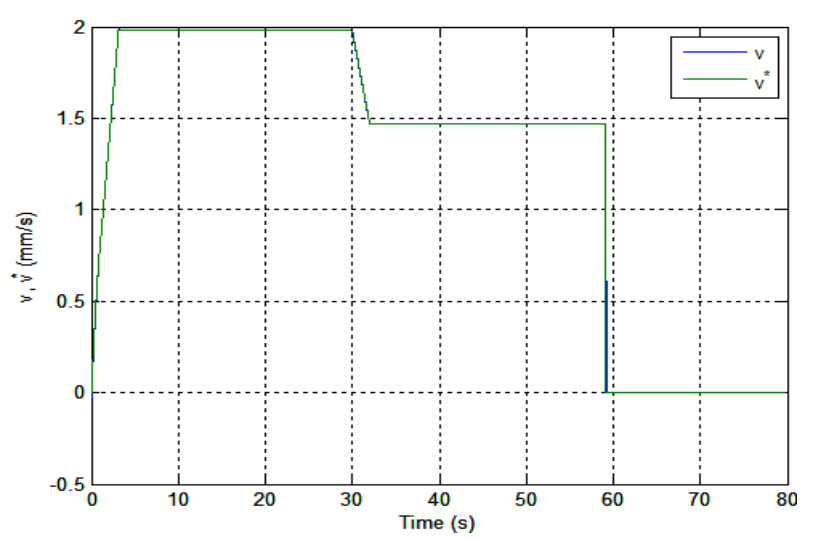

Fig. 10 Response and reference curves of $X$ base speed.

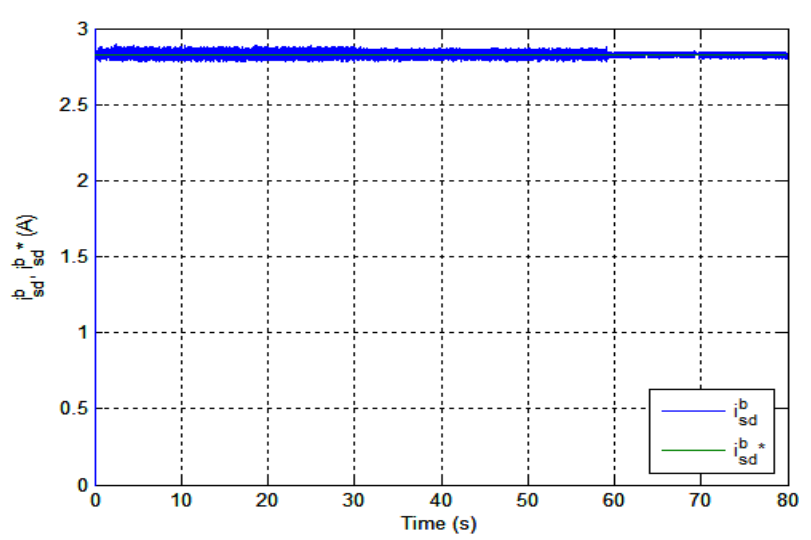

Fig. 11 Response and reference curves of the stator current in the $d$ component.

the current increase from $30 \mathrm{~s}$, moment from which the electromagnetic torque imposed on the three-phase induction motor was increased from $1 \mathrm{Nm}$ to $3 \mathrm{Nm}$.

For the analysis of neural estimation of the electromagnetic torque in Fig. 13, the ce electromagnetic torque curve obtained by modeling of 

the Feedrate of a Milling Machine

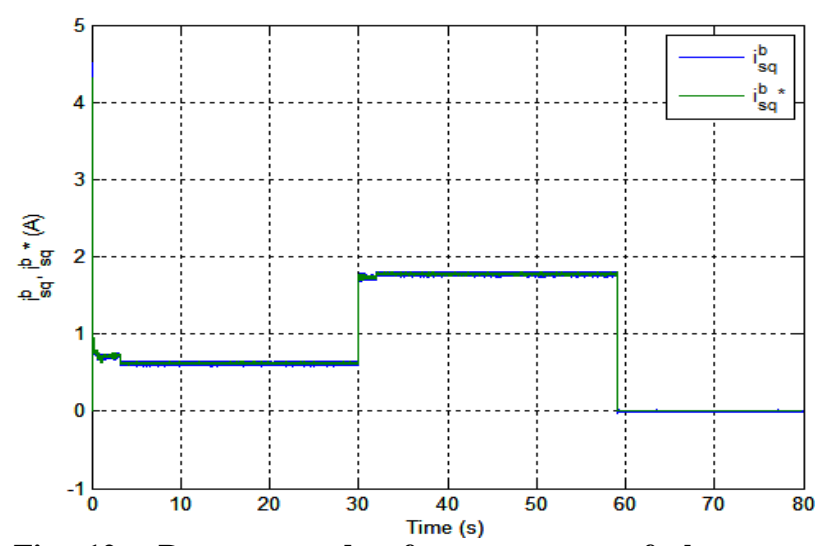

Fig. 12 Response and reference curves of the stator current in the $q$ component.

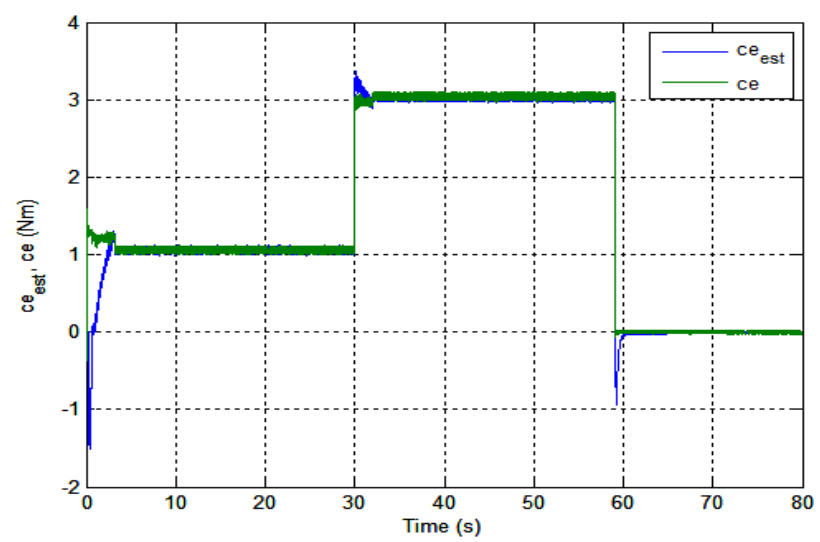

Fig. 13 Curves of the electromagnetic torque and of the estimated electromagnetic torque.

the motor using Eq. (10), and the $c e_{\text {est }}$ estimated electromagnetic torque curve obtained by Eq. (16) were observed. In this graphic, the behavior of $c e_{e s t}$ torque in the load transitory and in the steady state of estimation was verified. For applications of the first load $1 \mathrm{Nm}$ and the second load $3 \mathrm{Nm}$, distinctions between $c e$ and $c e_{e s t}$ curves were rarely observed in the steady state.

\subsection{Second Simulation}

In this simulation, firstly, a load of $-2 \mathrm{Nm}$ was applied, and after $45 \mathrm{~s}$ of operation, a $-5 \mathrm{Nm}$ load was applied.

In Fig. 14, the response and reference curves of angular position of the rotor are shown for a motor drive by step reference signal with amplitude of $-1,562.5$ rad. In Fig. 15, the response curve and the step reference of the position of the $X$ base with amplitude

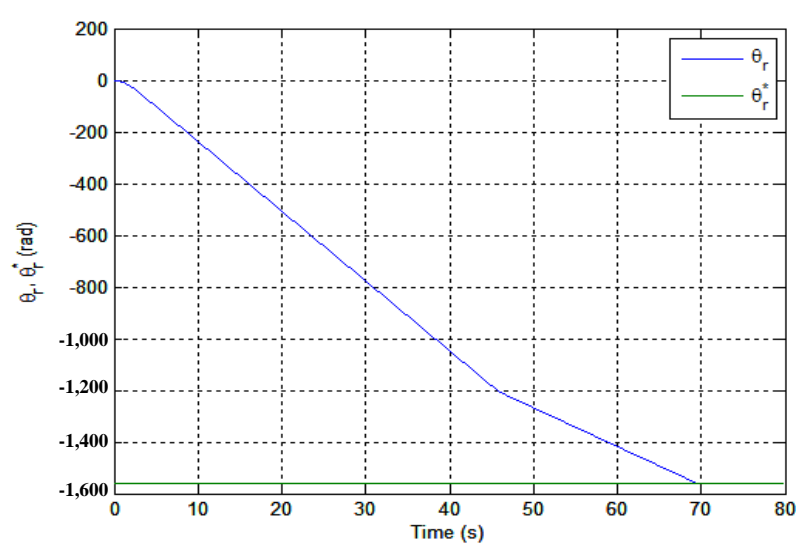

Fig. 14 Response and reference curves of the angular position of the rotor.

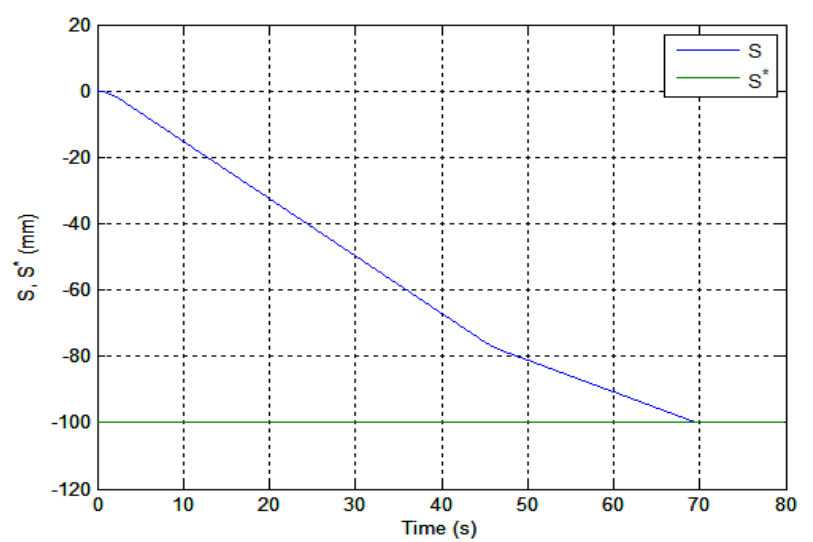

Fig. 15 Response and reference curves of the position of the $X$ base.

of $-100 \mathrm{~mm}$ are presented. This amplitude in millimeters is equivalent to a step of $-1,562.5 \mathrm{rad}$, corresponding to a position of $-100 \mathrm{~mm}$ in the $X$ base. Through the graphics of Figs. 14 and 15, it was possible to verify a settling time of $67.65 \mathrm{~s}$, a steady state error of $0.03 \%$ and non-occurrence of overshoot.

Then, in Fig. 16, the reference curve of the rotation speed of the rotor and the response curve obtained are shown. In this graphic, the excitation of the machine for speed ramp with amplitude of $-27 \mathrm{rad} / \mathrm{s}$ was in the downward direction, keeping constant speed until the instant of $45 \mathrm{~s}$. This constant speed of $-27 \mathrm{rad} / \mathrm{s}$ corresponded to the $\omega_{r}^{*}$ reference due to an estimation of electromagnetic torque of $-2 \mathrm{Nm}$. At the instant of 45 $\mathrm{s}$, due to torque estimation of $-5 \mathrm{Nm}$, a speed ramp with amplitude of $-15 \mathrm{rad} / \mathrm{s}$ was used, in the upward direction, remaining constant up to a drive $\omega_{r}^{*}$ at null value. 

the Feedrate of a Milling Machine

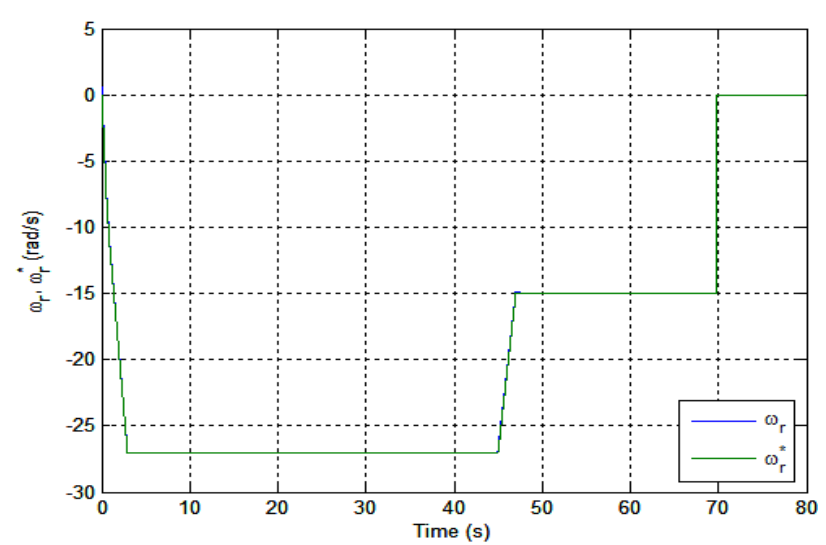

Fig. 16 Response and reference curves of rotational speed of the rotor.

In Fig. 17, the response and reference curves of the $X$ base speed are presented, in which the amplitude of $-1.728 \mathrm{~mm} / \mathrm{s}$ of the reference ramp is equivalent to the amplitude of $-27 \mathrm{rad} / \mathrm{s}$, and the amplitude of -0.96 $\mathrm{mm} / \mathrm{s}$ is equivalent to the amplitude of $-15 \mathrm{rad} / \mathrm{s}$. Through the graphics of Figs. 16 and 17, null steady state errors were observed in the time interval in which speed references were constant.

In Figs. 18 and 19, the components of the stator current $d$ and $q$ are presented, respectively. In these graphics, it was verified that the components of the stator current were controlled. In Fig. 19, from $45 \mathrm{~s}$, the increase of the module of the currents $i_{s q}^{b^{*}}$ and $i_{s q}^{b}$ was verified, because, from that instant, the module of the electromagnetic torque imposed on the motor was increased from $-2 \mathrm{Nm}$ to $-5 \mathrm{Nm}$.

In Fig. 20, the curves of the ce electromagnetic torque and of the $c e_{e s t}$ estimated electromagnetic torque

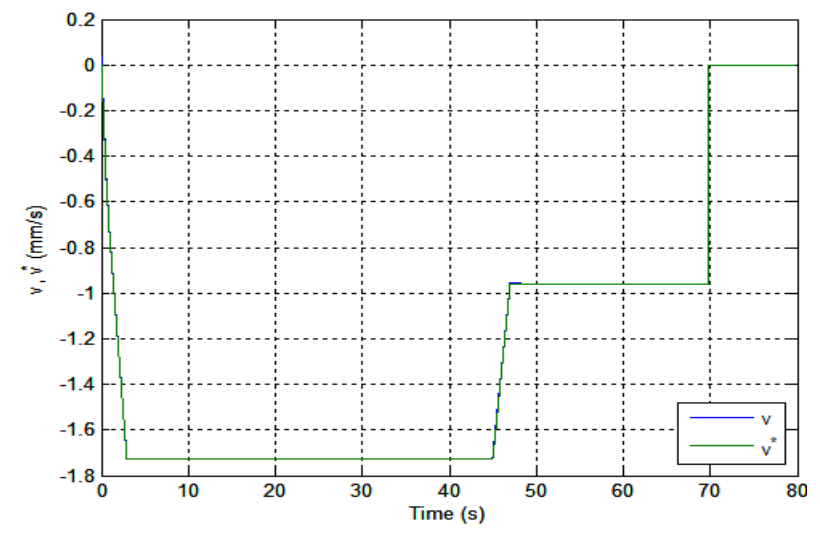

Fig. 17 Response and reference curves of the $X$ base speed.

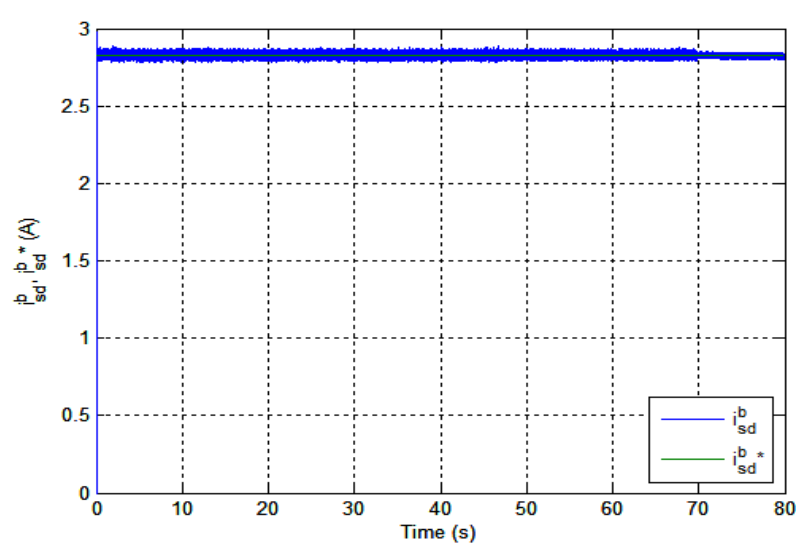

Fig. 18 Response and reference curves of the stator current in the $d$ component.

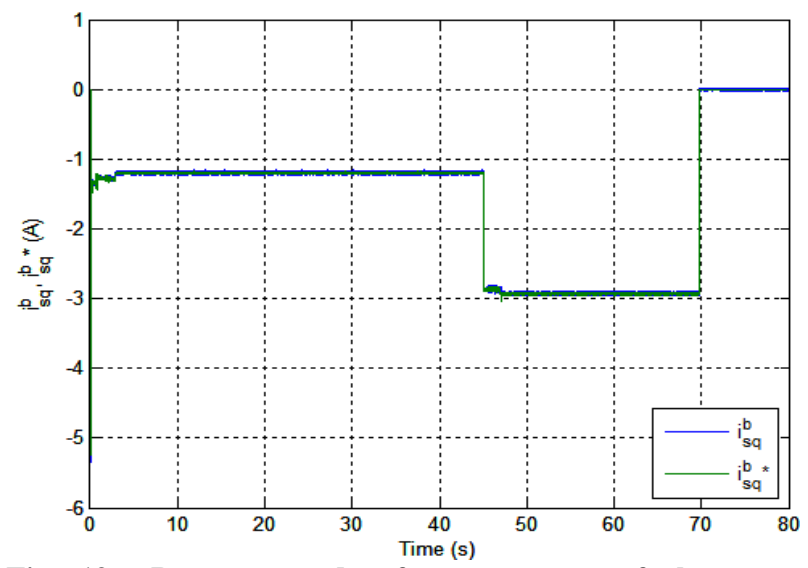

Fig. 19 Response and reference curves of the stator current in the $q$ component.

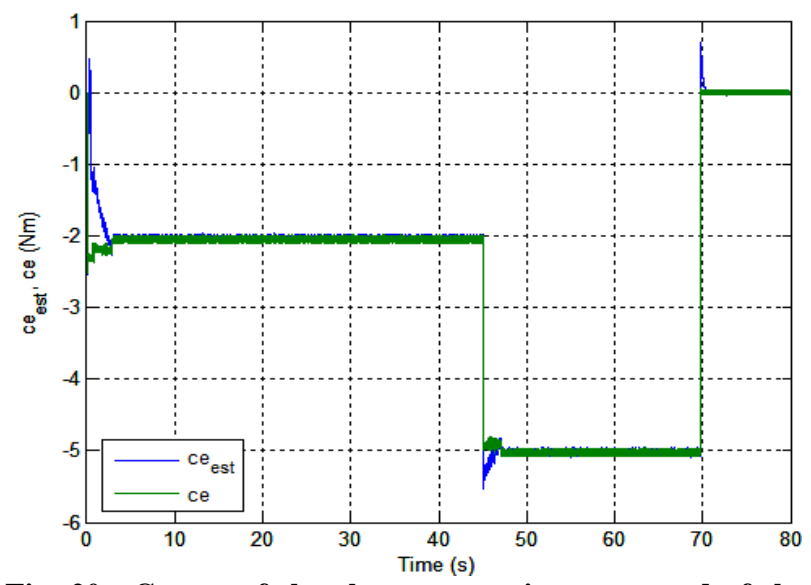

Fig. 20 Curves of the electromagnetic torque and of the estimated electromagnetic torque.

are shown. In this graphic, it was possible to verify the behavior of the $c e_{e s t}$ torque in the load transitory and in the steady state of estimation. In the steady state, distinctions between $c e$ and $c e_{e s t}$ curves were rarely observed. 


\section{Conclusions}

In this work, the simulation of a control system for application in a milling system was presented. A three-phase induction motor was used and controlled by intelligent control techniques to drive the milling machine table.

The performance of the control system was verified for the two directions of displacement of $X$ base of the table with changes in the electromagnetic torque imposed on the motor.

In analyzing the results, a criterion of $2 \%$ of the amplitudes of the references was used. Through the response curves of the two simulations, a maximum steady state error of $0.13 \%$ was verified for the variable position, not existing overshoot in any of the tests. For the speed, the fuzzy controller made possible the obtaining of null steady state errors in both simulations, at intervals drive with constant speeds. Regarding the electromagnetic torque, the convergence of the two signals of torque estimation was observed, obtaining small errors in comparing the curves of $c e$ and of $c e_{e s t}$ in the steady state.

The fuzzy controller of speed, using the TS method, and the neural estimator of the electromagnetic torque, using the LMS algorithm technique, made possible the obtaining of satisfactory performance of the dynamic functioning of the motor.

An important contribution of this work is the specification of the rotational speed of the rotor of a three-phase induction motor from the information of the signal of the estimated electromagnetic torque, using intelligent control techniques.

As perspective of future work, it is planned to carry out experimental tests in a milling machine, with the feedrate specified in real time from the machining of each material.

\section{References}

[1] C.A.F.C. Alves, Study of plasma nitriding applied to milling tools, M.Sc. Dissertation, Federal University of Rio Grande do Sul, 2002.

[2] L.M. Yue, F.H. Ya, L. Yuan, H.Z. Yu, An intelligent controller based on constant cutting force for 5-axis milling, in: International Conference on Information Technology and Computer Science, Ukraine, 2009, pp. 237-241.

[3] J.A.T. Altuna, Implementation of the direct method of vector control of an induction motor with stator flux orientation using DSP, M.Sc. Dissertation, State University of Campinas, 1997.

[4] L.A. Mozelli, Fuzzy control for takagi-sugeno systems: Improved conditions and applications, M.Sc. Dissertation, Federal University of Minas Gerais, 2008.

[5] T. Takagi, M. Sugeno, Fuzzy identification of systems and its application to modelling and control, IEEE Transactions on Systems, Man and Cybernetics 1 (1985) 116-132.

[6] I.S. Shaw, M.G. Simões, Fuzzy Control and Modeling, Edgard Blucher Ltda Publisher, São Paulo, SP, Brazil, 2004.

[7] A. Nigrini, Neural Networks for Pattern Recognition, The MIT Press, San Diego, 1993.

[8] D.E. Rumelhart, J.L. Mcclelland, Parallel Distributed Processing: Explorations in the Microstructure of Cognition, The MIT Press, San Diego, 1986.

[9] L.C. Leite, Identification of the conjugate of a sectorial induction machine by artificial neural networks, Ph.D. Thesis, State University of Campinas, 2003.

[10] X. Lin, A. Li, W. Zhang, Learning fuzzy logic based intelligent determination of feedrate for end milling operation, in: 6th International Conference on Intelligent Systems Design and Applications, China, 2006.

[11] P.B. Severino, A study of estimation of flux and conjugate in three-phase induction motors-implementation using DSP, M.Sc. Dissertation, Federal University of Uberlândia, 2005.

[12] C.E. Milhor, Proposal of a Takagi-Sugeno fuzzy controller with $H_{\infty}$ performance for regulation of idling in otto cycle engines, Ph.D. Thesis, University of São Paulo, 2008 . 